This is an Accepted Manuscript of an article published by Taylor \& Francis in Innovation: The European Journal of Social Science Research on 24 Jan 2012, available online: http://dx.doi.org/10.1080/13511610.1999.9968597

\title{
FocUS GROUPS IN INTEGRATED ASSESSMENT: A Micro-Cosmos for Reflexive Modernization
}

\author{
(Accepted for Innovation - The European Journal of Social Sciences, Vol. 3/99)
}

Carlo C. Jaeger "s, Ralf Schüle ", Bernd Kasemir s

" Dept. of Sociology, Darmstadt University of Technology, Germany.

'Siviss Federal Institute for Environmental Science and Technology, Dübendorf, Switzerland.

\begin{abstract}
${ }^{1}$
Like every society, today's global society has a body of knowledge which is taken for granted in everyday life. This knowledge, which is organized around the prospect of modernization, is currently challenged in several ways. One of these challenges concerns the risks of global environmental change. We investigate the hypothesis that the conceptual machinery of modernization is experiencing a far-reaching transformation whose outcome may be labelled as reflexive modernization. For this purpose, we propose a new methodology based on focus groups embedded in a process of integrated environmental assessment. The methodology yields promising results which are consistent with the hypothesis. They point to further implications of the hypothesis of reflexive modernization which are both interesting for theoretically oriented research and relevant for policy making.
\end{abstract}

Keywords: Reflexive Modernization, Integrated Assessment, Focus Groups, Ideal Types, Human Dimensions of Global Change.

1 The paper is based on research performed in the European project ULYSSES - Urban Lifestyles, Sustainability and Integrated Environmental Assessment, financed by DGXII of the European Commission (Fourth Framework Program), and in the Swiss project CLEAR, financed by the Swiss NSF (Priority Program Environment). We are grateful for discussions with Ulrich Beck, Hadi Dowlatabadi, Ottmar Edenhofer, Cordula Kropp, Ted Parson, Angelika Poferl, Ortwin Renn, and to the collaborators of the ULYSSES and CLEAR projects. The usual disclaimers apply.

An earlier version of this paper was presented at the European Sociological Association Conference, University of Essex, Colchester, GB, 27-30 August, 1997. 


\section{Introduction}

A multitude of research efforts in the social and natural sciences is currently devoted to the causes, the internal dynamics and the possible impacts of global environmental change. At the same time, one social impact is already observable: the institutional fabric of highly industrialized societies with national governments based on representative democracies has serious difficulties to cope with environmental risks of this category.

Major uncertainties surround the various conceivable social and economic impacts of global environmental change. But major uncertainties also surround the following question: with what kind of democratic institutions and procedures can modern societies evaluate the relevant risks and possible policy measures in an adequate manner? These latter uncertainties amount to a serious challenge for the prospect of modernization, which more than ever frames current societal developments.

In fact, the last few years have been marked by an astonishing triumph of modernization. With the breakdown of communism, there seems to be only one conceivable type of future worldwide. Its concept of market-based progress is built upon the idea of modernization. Simultaneously, however, the awareness of global environmental change raises serious doubts about the plausibility of this future. We are experiencing an unprecedented tension between the apparent inevitability of modernization and the suspicion that its course may not be viable for much longer.

It is tempting to simply ignore one of the two horns of this dilemma. Heralds of postmodernism try to do so with regard to the powver of modernization. Believers in an economy without checks and balances counter with much greater success by belittling concerns about global environmental change. In parallel to these intellectual controrersies, similar conflicting knowledge claims arise in the symbolic universe of lay persons.

Under these circumstances, the following hypothesis - due to Beck, Giddens and Lash (1994) - deserves careful consideration: the conceptual machinery of modernization is currently experiencing a far-reaching transformation whose outcome may be labeled as reflexive modernization.

We relate this hypothesis to the problem of global environmental risks and to different modes of the social construction of reality (section 2). Our discussion of the hypothesis will be based on the observation that, like every society, today's global society has a body of knowledge which is taken for granted in everyday life. To investigate the hypothesis empirically, we propose a new methodology based on focus groups embedded in a process of integrated environmental assessment (3). The methodology yields promising results which are consistent with the hypothesis (4). The results point to further implications for the hypothesis of reflexive modernization, for the methodology of IA-focus groups, and for policy making (5). 
Focus Groups in Integrated Assessment: A Micro-Cosmos for Reflexive Modernization

\section{The Problem}

\subsection{Reflexive Modernization}

With regard to global environmental change, science plays an ambiguous role. On the one hand, the dangers of ozone depletion, climate change and similar processes could be detected only thanks to the fruits of scientific progress. On the other hand, one may well argue that these dangers result from other aspects of the very same scientific progress: without science, humankind would hardly have developed the pollutants which are currently depleting the stratospheric ozone layer or the ones which are enhancing the natural greenhouse effect of the atmosphere.

One way to address this contradiction is by studying the tension between "realist" interpretations of science, which treat scientific knowledge claims as testable descriptions of "reality out there", and "constructivist" interpretations, which treat scientific knowledge as the sophisticated elaboration of a conceptual apparatus which leads to "constructed realities". Realist interpretations tend to foster trust in science, while constructivist interpretations tend to undermine such trust. Historically, scientists have tended to develop self-concepts along realist lines. Realism has greatly strengthened the belief that scientific progress is a movement towards truth, which deserves widespread support. In this view, environmental problems require more knowledge of the sort provided by science. In a constructivist view, however, realism is a misperception based on a lack of awareness for how human beings continuously construct the realities which they inhabit. This misperception is seen to cause environmental problems because it leads to hybris in the application of science.

In environmental sociology, Buttel and Taylor (1992) can be associated with a constructivist approach, Dunlap and Catton (1994) with a more realist one. Along these lines there is a danger, however, to loose sight of an important sociological problem - the role of science in shaping the relation between society and its environment - by getting enmeshed in somewhat sterile epistemological debates. Spargaren (1997) has argued that a more fruitful approach would focus on the possibility of reflexive modernization, and we will follow his suggestion here. This will lead us to reconsider the issue of the social construction of reality not primarily as an epistemological question, but as a sociological problem amenable to empirical research.

So far, the most comprehensive argument about reflexive modernization has been proposed by Beck (1994a). He builds on earlier work (Beck 1986/1992) where he has discussed the emergence of global risks as a crucial consequence of modernity. In response to risks engendered by modernization itself, the capacity for criticism which modernity had directed towards older social traditions is now turned towards the process of modernization itself. The direction of technical and scientific progress ceases to be an autonomous drive for the rest of society and becomes an object of critical public debate. This implies a "radicalization of modernity", it becomes reflexive. As Beck points out, this transition dissolves the premises of industrial society and opens the path into "other modernities". The research challenge implied by the notion of reflexive modernity, then, is to investigate the paths of social development which become possible with this transition. 
Beck's notion of a self-endangering modernity resonates with arguments by Giddens. Both authors emphasize institutional changes in the face of global risks and uncertainties. For Giddens, modernity is characterized by the project to consciously organize social relationships and society's relationship to nature (Giddens, 1994b; see also: Baumann 1982). The attempt to "colonize the future", however, has led to global self-manufactured uncertainties and risks. This marks the crucial paradox of modernity (Giddens 1990, 1994a).

Giddens distinguishes between four major issues in the globalization of risks: the endangerment of global eco-systems, the development of poverty, the existence of weapons for mass destruction, and the suppression of democratic human rights. According to Giddens, the new dimension of risks affects scientific inquiry and policy-related scientific expertise. Conceptually, the clear distinction between nature and society cannot be maintained. Due to the extension of control about the physical environment, nature cannot be represented and understood without including the moral dimension. Scientific inquiry looses its claim of uncontested authority and its role as a "neutral referee" in social conflicts. In particular, categories such as expert and lay knowledge can only be understood as context-specific terms: experts are granted a "provisional claim" of authority only. In dealing with the risks produced by modernization, this implies a reflexivity of both the way in which individual life is organized and the way in which expert knowledge is accepted.

The work of Giddens and Beck has been criticized for their allegedly objectivist understanding of risk and of the role of trust in modern society. In particular, they have been taken to task for neglecting the reflexive potentials of lay people (Wynne 1996). Along different, but related lines, Beck has been criticized for ignoring the unavoidable cultural dimensions of any form of rationality and reflection - the cultural embeddedness of social interaction (Alexander and Smith, 1996). Another variation of this theme is the claim that Beck ignores the esthetical and normative dimensions of reflections on risk (Lash and Urry, 1994; Lash, 1994).

\subsection{Knowledge in Everyday Life}

These criticisms are not fatal for the notion of reflexive modernization, however. They can lead to an improvement of this notion by taking into account how modernization affects the social processes by which a shared perception of reality is generated and maintained in everyday life. For this purpose, it is useful to reconsider how Berger and Luckmann (1966) introduced the idea of "the social construction of reality" in the sociological literature. Their focus was on those beliefs which are taken for granted in everyday life. They stressed the fact that human societies differ greatly in the content of those beliefs, but that they share certain mechanisms for maintaining a relatively stable body of such beliefs. Pivotal amongst the relevant mechanisms are conversations in face-to-face settings.

Berger and Luckmann emphasized the fact that before the advent of modernization, societies usually were characterized by a comprehensive symbolic universe which provided an integrated framework for the interpretation and legitimization of human actions. Modernization, in their understanding, involved a symbolic universe, too, but it had two peculiar features.

First, it offered and enforced a pluralic concetual machinery. A crucial step towards pluralism was made with the treatment of human values. The symbolic 
universes of earlier societies were organized around some set of common values which all members of the respective societies were supposed and expected to share. But now it became common knowledge in everyday life that different people have different values, interests, preferences etc., and that it is unnecessary and actually harmful to try to eliminate these differences. One may describe this state of affairs by saying that the symbolic universe of modernization was organized around "metavalues" like tolerance, freedom, and the pursuit of happiness. These meta-values differ from the values of earlier societies precisely by creating the mental space in which widely different religious beliefs, sexual orientations, political interests, aesthetic tastes and moral views can coexist.

Second, the symbolic universe of modernization involved a powerful weaponry for debunking the symbolic universes of earlier societies. Whatever shared beliefs such societies maintain, they can always be shown to serve important goals pursued by various members of these societies. This is bound to be so because any symbolic universe is an integrated whole composed of many interacting elements, fostering a match between legitimate goals of individual action and beliefs about the world at large. From the point of view of modernization, this could always be interpreted as showing that these beliefs are maintained primarily because they serve those goals. Moreover, the symbolic universe of modernization was systematically geared to scientific institutions which did not exist in earlier societies. Thus, wherever beliefs maintained by such societies differed from those of modern society, they could be described as instances of social ignorance caused by the absence of scientific institutions. A combined diagnosis of ignorance and rested interests could then be used to explain and undermine the symbolic universes of more traditional societies. This is one reason why modernization has not led to one human society coexisting with other societies, but rather to an aggressive process which tends to reach the whole living humankind.

Meanwhile, modernization has become a tradition of its own. We designate this tradition as simple modernization, in contrast with reflexive modernization. Simple modernization treats its own knowledge base as the one and only global knowledge, while it treats all other knowledge as local knowledge which can and must be set in this frame (Jaeger, 1996). Reflexive modernization treats the knowledge base of modern society as local knowledge like other bodies of knowledge which it may encounter by crossing geographical, cultural, and historical barriers. If global knowledge is to emerge, then out of such encounters.

Reflexive modernization sets in precisely by turning the critical apparatus of modernization towards itself - by relativizing the relativizers (Berger, 1969). This need not lead to self-destruction, quite the opposite, it may well enhance selfawareness. It is too early to say where this paradoxical step will lead, but some suggestions have been made. Giddens (1994b) has stressed the different relation to traditions. Reflexive modernization leads to a post-traditional society, not in the sense that there will be no traditions anymore, but in the sense that people actually choose the traditions from which they let their lives be shaped.

Therefore, reflexive modernization leads to new roles for experts and their knowledge (Beck 1994b, Funtowicz and Ravetz, 1991, 1992). They cannot operate anymore as an ultimate standard, a neutral referee for knowledge and ignorance, because they are subje-t to the relativization of modern skepticism, too. On the other hand, they are more indispensable than ever because everyday life is permeated by 
technologies and expert systems which cannot be handled without scientific inquiry. Funtowicz and Ravetz $(1991,1992)$ have discussed this transition by distinguishing different levels of uncertainty environmental science has to deal with, ranging from technical through methodological even to epistemological dimensions. In the face of global environmental risks, limited expert knowledge becomes part of the problem especially when conflicting knowledge claims and research traditions come into play. Therefore, the debate about global environmental change is not anymore a discussion within limited circles of scientific peers but a matter of public interest. The consequences are twofold: On the one hand, the definition of research problems is no more located solely in the scientific community. Public debate and political decisionmakers influence this process, too. On the other hand, science becomes a strategic variable which is used in political debates to strengthen different positions (Godard, 1992).

A major drawback of the literature about reflexive modernization is its tendency to avoid the challenges of empirical research. Research results are often discussed, but arguments which lead to new empirical results are rare. This is due to a serious difficulty. To a large degree, the methodological canon at the disposal of the sociologist today is itself a product of simple modernization. This is quite obvious for many methods of quantitative research. But one should not forget that even the qualitative methods developed by anthropologists have been developed mainly as tools of modern society to come to terms with the knowledge systems of pre-modern societies. The study of reflexive modernization will certainly rely on existing tools of social research. But it will require creative methodological developments in order to grasp the processes by which the social construction of reality itself gradually becomes a conscious element of everyday life. One promising approach positions the researcher as an active but methodically controlled participant in face-to-face conversations about issues involving problematic knowledge claims by scientific experts. We propose a methodology which fits this approach in the next section.

\section{Developing a Suitable Methodology}

\subsection{Participatory Planning and Focus Groups}

Recently, promising attempts to develop methodologies which resonate with reflexive modernization have been undertaken in environmental planning and technology assessment. Traditional planning procedures are characterized by a strict distinction into separate phases (generation of information, definition of goals, implementation, examination of results), which fit with the perspective of simple modernization. Newer procedures, however, tend to remove this distinction by involving relevant actors even in the first phases of the planning process. Several such procedures aim at achieving consensual agreements on controversial problems of urban and environmental planning. Most of these procedures have been applied in the context of practical planning problems, and several efforts have been undertaken to integrate them into a theoretical framework. Especially the Theory of Communicative Action by Habermas (1982) has been an important but not the only theoretical contribution to justify and design these kinds of procedures (Jaeger et al., 1995; Jaeger et al., 1999; O’Hara, 1996, Renn, 1993; Renn, 1995). 
In environmental planning, three different types of procedures can be distinguished (Schuile, 1996): A first approach aims at integrating the judgements and the recommendations of lay-persons in public planning and technology assessment. They include procedures such as planning cells (Dienel, 1992; Dienel and Renn, 1995), citizen juries (Cosby, 1995), citizen advisory committees (Lynn and Busenberg, 1995) and consensus conferences (Joss and Durant, 1994). A second approach aims at formulating consensual targets for regional or urban development by involving different interest groups. In contrast to the first type of procedures, the focus is not on the involvement of lay-persons but on the stakeholders concerned by a specific decision (Caulfield and Minnery, 1994; Sellnow, 1994). The third procedure, labeled as Environmental Dispute Resolution or Mediation, aims at resolving environmental conflicts by the appointment of a mediator (Amy, 1987; Hoffmann-Riem 1988; Folger 1994). In most participatory procedures expert input is used to structure and to inform the discussions.

While these methods are all directed at decision making, they have two interesting relations to a well-known instrument of social research: the focus group. First, they try to mobilize the potential of face-to-face discussions in small groups to generate images and perceptions of a topic under discussion. And second, they trigger these discussions by confronting the group with an initial incentive such as pictures, movies, photographs or oral contributions.

Focus groups have been used in applied social science for more than 50 years (Merton, 1946, 1987; Morgan and Krueger, 1997; Greenbaum, 1998; Barbour and Kitzinger, 1999). The crucial feature of this methodology is to confront a group of participants with a common input (like a video-clip) and to trigger a discussion about this input. In this sense, focus groups combine elements of the focused interview and the group discussion, guided by a skilled moderator. The spectrum in which focus groups have been used until now ranges from evaluation (Krueger, 19SS) and media research (Conner et.al., 1991) through communications and organizational research (Byers and Wilcox, 1991) to decision research (Steward and Shamdasani, 1990).

Focus groups are widely used in applied social research, especially to study the dynamics of emotions and arguments triggered by new information, e.g. about a politician or about a commercial product. Surprisingly, perhaps, the literature on focus groups mostly has only introductory character (for a comprehensive discussion see Duerrenberger 1997 et al.) still inviting an in-depth methodological study.

Attempts to use focus groups in policy related risk communication and Local Agenda 21 initiatives (Desvouges and Smith, 1988; Young, 1996) bring the methodology close to procedures of participatory planning and technology assessment. In the field of environmental risks several authors have used focus groups to investigate public understanding of global warming and related issues (Kempton, 1991a; 1991b; Bostrom, 1994; Löfstedt, 1991; Dahinden et.al., 1994) including environmental values and mental models (Burgess et al., 1988; Bostrom et al., 1992).

The use of focus groups seems especially promising in the assessment of environmental risks. As Kasemir et al. (1996) argue with regard to climatic risks: 
"A public discussion on climate-change policy zvithout sufficient scientific input would be highly ineffective, zuhile scientific modeling without sufficient input from public discussion risks focusing on irrelevant issues while ignoring questions of interest to the public."

Focus groups can help to blend the knowledge base of laypersons with the expert knowledge relevant for specific environmental risks. For this purpose, however, expert knowledge must be available in a suitable format. This requirement is far from trivial. In the past years, however, promising efforts in this direction have been undertaken in the field of Integrated Assessment (IA).

\subsection{Integrated Assessment (IA)}

IA has developed as a means to tackle policy problems whose solution requires a wide variety of disciplines. Such problems are especially pervasive in environmental studies. In general terms, Parson (1994:2) defines the task of IA as follows: "... a) to seek to provide information of use to some significant decision-maker rather than merely advancing understanding for its own sake and b) that it bring together a broader set of areas, methods, styles of study, or degrees of confidence, than would ty'pically characterize a study of the same issue within the boundary of a single research discipline."

Integrated assessment is closely related to methodologies of environmental (impact) or social impact assessment, although IA is characterized by its claim to analyze the complex interactions of geo-, bio-, and sociosphere (Robinson, 1995). In addition, IA is also related to decision-support or expert systems, scenario methods and teaching or training games, insofar as they have been applied in the field of political decisionmaking (Dowlatabadi, 1994; Toth, 1994; Toth, 1995; Parson, 1994).

The task of IA is often tackled with the help of computer models. A paradigmatic example is the RAINS model, which was developed in 1983 at the International Institute of Applied Systems Research (IIASA) in Laxenburg, Austria (Alcamo et. al. 1990). Its objective was to simulate possible scenarios of the impact of acid rain. While its basic assumptions certainly left room for improvement, RAINS was utilized in the international acid rain negotiations in the early $1980^{\circ} \mathrm{s}$. The model was considered as a great success because it demonstrated a high degree of scientific credibility, flexibility, interactive nature, level of spatial resolution and level of integration. Meanivhile, a series of IA models has been developed, especially in the field of climate change.

IA models can present expert knowledge on a practical problem in a format which is accessible to non-experts. Therefore, one may consider using IA models as input for focus groups. Recently, the inclusion of lay-people in IA has been proposed (Funtowicz 1994; Jaeger et.al. , 1995; Bailey et.al. 1995) and first efforts in this direction are under way. We designate the combination of IA models and group discussions with lay-people as IA-Focus Groups (Kasemir et. al. 1998). Such a combination can draw on the prominent role of expert panels using computer models in IA. 
Focus Groups in Integrated Assessment: A Micro-Cosmos for Reflexive Modernization

\subsection{IA-Focus Groups}

IA-Focus Groups are a promising method for the study of reflexive modernization for the following reasons. First, they establish an interface between expert knowledge and the knowledge taken for granted by laypersons in everyday life. Second, they do so by bringing about face-to-face conversations. Third, they are well suited to investigate environmental risks arising as a consequence of modernization. And fourth, they can provide a wealth of empirical data, including minutes, audio and video tapes, collages and texts produced by the groups, as well as additional questionnaire answers by the group members.

In this paper, we rely on work carried on in the project ULYSSES (Jaeger et. al. 1995; Kasemir et al., 1997). In the ULYSSES project, integrated computer models are used as input for discussions in IA-focus groups. Data are collected in parallel in Sweden, the UK, Germany, Switzerland, Spain, Italy, and Greece. The present paper relies on experiences made with IA-Focus Groups in the Frankfurt area during the main phase of the project. The data used here have been mainly collected from nine IA-focus groups (45 discussion sessions) with lay-people run in early 1997, and in part also from one session (policy panel) carried out with regional stakeholders. The basic pattern of the lay groups is given by a group size of about seven participants who meet five times for about two hours. Some variations around this design have been tested. In order to represent a heterogeneous spectrum of participants, recruitment criteria were applied in the process of recruitment. ${ }^{2}$ The participants are ordinary citizen selected at random from the general population or a specific sub-population (like students or lower-class people). In the policy panel, the participants were selected on the basis of a stakeholder analysis at a regional scale. More details of the

2 The criteria applied in the process of recruitment were developed during the research process. Whilst the participants of the first five IA-Focus Groups in the Frankfurt area were recruited by random phone calls, in the following four groups below criteria were applied:

- Place of residence: All participants should be inhabitants of the Frankfurt area.

- Age: At least 1/3 of the participants should be younger and at least $1 / 3$ should be older than 50 years.

- Gender: At least $1 / 3$ of the participants should be male and at least $1 / 2$ should be female.

- Occupation and Education: At least $1 / 3$ of participants should be manually working people (employees or entrepreneurs) and no more than $1 / 3$ university graduates.

- Income: At least $1 / 3$ of the participants should have relatively low income (threshold below the average household income) and at least $1 / 3$ should have relatively high income (some threshold above the average household income).

- Attitudes tovards the Environment: In order to avoid a 'green' bias in our groups. two questions were asked when contacting potential group participants:

a) "Please mention the three most important problems in our societr toda: "

At least $1 / 3$ of participants should have mentioned the environment, at least $1 / 3$ of the participants should not have mentioned it.

b) "Would you be in favor of more environmental regulation (taxes and law's)?"

At least $1 / 3$ of participants should have agreed, at least $1 / 3$ should have disagreed.

Recruitment according to these criteria was done either by the research teams themselves (using random phone contacts and subsequent screening for the criteria) or by professional recruitment agencies. 
IA-Focus Groups run with lay-people are described below. (This design follows closely the one described in Dürrenberger et al, 1997 and Kasemir et al, 1999).

\section{Process description}

As a rule, the IA-focus groups used here comprise five session. The first session is dedicated to a free discussion of the overall theme, namely climate change, and to an introduction of the overall task. The discussion is triggered by the experience of producing and discussing a collage about climate change. The task of be done in session five is set as the drafting. of a citizens' report about climate change based on group discussions stimulated by computer models related to the same topic. In sessions two to four, two computer models are introduced, one focussed on impacts of climate change with a global scope, the other one focussed on options for mitigating greenhouse gas emissions in the region under study. Various combinations out of four models have been used: the models IMAGE (Alcamo, 1994) and TARGETS (Rotmans and DeVries, 1997) for impacts, the PoleStar model (SEI, 1996) and the "personal CO2-calculator" by Christoph Schlumpf et.al. (EAWAG, Switzerland) for options. The groups are directed by a moderator, who is assisted by a model moderator when it comes to computer presentations. The groups are invited to play' with the assumptions of the models and to discuss the computed outcomes.

A discussion about desirable and undesirable scenarios on the global level at the end of the second session leads to a discussion on policy goals and measures at the regional level, contents of the third and fourth session. In order to assess the impact of the goals of CO2-reduction in the Frankfurt area, a regional decision framework, fed with regional data, is introduced at the end of the third and the beginning of the fourth session. The regional scenarios offered by this decision framework are the basis for the discussion on acceptable and plausible measures in the regional traffic and household sector. While in session four policy implementations are discussed, a citizen report is written by the participants in session five. In each of the preceding sessions, material for the citizens' report is collected as a preparation for this.

\section{Data collection and analysis}

All the sessions are recorded by video and audio tapes. Additionally, a minute-taker takes notes of the form and content of each discussion. In order to reflect both the role of the moderators in the group process and the group process itself, the research team (group moderator, model moderator, minutes-taker and independent observers) meets after each session and analyzes the discussion. ${ }^{3}$

The further analysis is inspired by the concept of ideal types developed by Max Weber (Weber, 1949; for a recent discussion see Hirsch-Hadorn, 1997; Ringer, 1997; Schüle, 1999b). Ideal types have been somewhat under-utilized in past decades of empirical social research. This, however, can be expected to change with the increasing focus on interpretative analysis in qualitative social research, for which ideal types are especially suited. In the ideal type method proposed here, the researcher tries to organize a multitude of empirical observations not by averaging, but by generating

3 A synoptic overview of the material used in the focus groups (discussion guide etc.), the participants (demographic data), the input (material presented by the model moderator) and the output (tapes, minutes, statements) of the groups, the used models etc. is available in Schüle (1999a) 
ideal types via the following procedure: First, the researcher puts a quite one-sided emphasis on one selected angle of reality. That means that he or she prepares to look at the empirical material relative to what is considered an interesting perspective for the study undertaken. Such perspectives should be moral orientations which are relevant for the social system under consideration. In this step selection criteria for characteristic features which will later form the content of the ideal type are defined. Second, from the multitude of phenomena in the empirical material those instances are selected which seem especially relevant relative to the criteria defined. Third, from these selected phenomena a coherent picture is composed. On this basis, the dynamic interaction between various ideal types may then be considered.

In our analysis the material was analyzed by at least two researchers with an iteration of three main steps. First, rough sketches of possible contents of ideal types which seemed relevant for the material under consideration (i.e. selection criteria of characteristic features) were formulated in a provisional way. In the present case, these were the the ideal types of simple and reflective modernization. Second, the notes were condensed by means of significant quotations, often arranged in tabular form for purposes of synopsis. At this stage, the influence of exogenous factors like gender, social background, exposition to computer models, etc. on the IA-focus groups may be considered. On this basis more detailed material was brought in for example by transcribing specific portions of the tapes, and analyzing other material (collages, citizen's reports, etc.). Third, we begin to develop coherent pictures of the possible ideal types from these selected parts of the material. After that, the procedure started again until the two researchers reached a reasonably stable analysis of the material. Other possibilities for analyzing IA-focus groups exist and will be explored in the ULYSSES project. In the present paper, we stick to the procedure just described.

With regard to simple and reflexive modernization, this procedure has led to a differentiated treatment of these two ideal types. Simple modernization was treated along with two forms of opposition to it: fear of progress and moral criticism. Neither of the two can be unambiguously associated with reflexive modernization, although both can lead towards it. As for reflexive modernization, the topics of uncertainty, of trust in expert models, and of problem-solving have been instrumental in organizing the results, as will be shown in the following section.

\section{Empirical Findings}

\subsection{Simple Modernization}

As discussed in section 2, simple modernization has developed a symbolic universe centered around science. An important feature of this symbolic universe is the split between facts and values. The former are checked in an inter-subjectively binding VIay by science. The latter may differ from individual to individual, as long as all individuals accept to subordinate their value-orientations to judgements of costs and benefits for different courses of collective action. Such judgements may be produced by science, by markets, or by majority vote.

As we will discuss in this section, the ideal type of simple modernization is not dominant in our IA-focus groups. This is clearly consistent with the hypothesis of 
reflexive modernization. However, the shadow of simple modernization is clearly present in at least three ways. First, scientific expertise still provides the authoritative source for essential knowledge about environmental problems. Second, the dynamics of simple modernization is perceived as an important feature of the world we live in, although it triggers highly ambivalent feelings. And third, moral reasoning questions the idea that individuals should always be prepared to frame their value judgements in terms of costs and benefits.

\subsubsection{Fading Influence of Simple Modernization}

Several conversation segments imply express robust confidence in scientific progress. This may concern cognitive progress in the search for scientific truth:

"Clearly there are so many climate computations, and they even contradict each other, but some day scientists, programmers etc. will know somewhat more precisely, in thirty years or twenty years, whlen looking back, what has changed."

Moreover, the search for scientific truth may be seen as part of a more comprehensive progress, as helpful in the attainment of a desirable goal. When discussing the use of computer models of climate change, one participant states:

"For me personally an interesting issue is, for example, there are many people who believe that they don't need to do anything. If with such a model one can clarify, or one can showe: now already there is a need to take action, and not only in 30 or 50 years, then this would be a zaluable contribution. It seems to me that this should be possible, to show such a situation."

Simple modernization combines scientific knowledge with moral values to improve the world by human action. Such a perspective is rather close to the following statement.

"One can quarrel about the details of hou single variables have been modeled, but in the end in my view this has no great mutritional value. The question here is: do I now believe exactly this one, or something else? Thie tendencies have leen confirmed by many other studies, too, ant there is a definite need for action. I would love to enter this debate. But it leads nowhere, does it? We are now discussing the credibility of such scenarios, instead of discussing what possibilities there are to reduce... [negative reaction in the group]. Before you react, I i'ould like to add one thing: Of course it is important to know with what controls I can have the greatest effect."

This group's negative reaction to the "let's get things done" approach is no isolated phenomenon. Out of nine groups, only a single one used simple modernization as the taken-for-granted background for its debate. And not only does this framework rarely appear in the conversation - where it does appear it often runs into strong opposition.

\subsubsection{Fear of Progress}

One form of this opposition concerns the taken-for-granted optimism which simple modernization holds with regard to progress. The rery prospect of climate change is a powerful trigger for expressing an explicit fear of the future:

"I am afraid, for example, once a massive icarming has happened or the atmosphere has been mangled, is this really a process which can be reiersed once again? Because 
Focus Groups in Integrated Assessment: A Micro-Cosmos for Reflexive Modernization

there is always this attitude, zwell, if something dreadful occurs, then we sit doivn together and manage the problem."

Or, when discussing the interaction with a computer model:

Mot: "What did you find impressive about the model, what did you find less
inturessive?"

A: "[...] Well wherever one tried a turnaround towards something lower - when lower would be better - it always z'ent up - despite breaks. I just zoonder, where does this end upruards, how will this go on? The year 2100 we still can figure out. I will not see it. [...] This makes me fear the future, for those who come after me, that things go up that way, that things go on that way."

Another contribution:

"I was surprised, negatively impressed in the way of, I would want to say, fear concerning the future."

We are a far cry from the unswerving confidence that tomorrow will be better than yesterday, which marked the age of simple modernization.

\subsubsection{Morals against Modernity}

Another level at which the perspective of simple modernization has run into fierce opposition in at least some IA focus groups is the moral ground. An important example concerns the role of benefit cost analysis. The belief that an appropriate course of collective action can be identified by maximizing the difference between benefits and costs is a hallmark of simple modernization. In this riew, non-market values can be translated into market values, differing value orientations and attitudes towards risk can be handled by market mechanisms or compensations, and a sound collective decision can be reached without any need to enter moral debates. Clearly, benefit cost analysis can also be used in a more reflexive mode. But one of the interesting results of the IA-focus groups concerns the straightforward use of benefit cost analysis in the integrated assessment of climate change. While such an approach is a major - although by no means the only - line of research in studies of climate change, it is alien to the.thinking of all but one of our IA-focus groups. The issue comes to the fore in the following exchange between three participants and the moderator:

A: "If I hai'e understoot this correctly, that some economists come and try to compute what is cheaper, to pay for the consequences of envirommental disaster or ... Basically, this is cynical, if I have understout that this is hou they do it. If it is cheaper than what I would need to do now', to ac'oid it."

Mod: "Why zoould you say this is cynical?"

A: "Because I think with regard to the people w'to suffer because of it this is cynical."

$B:$ "But a'e ourselues do this all the time."

A: "What?"

B: "Anytime you buy yourself something, you check with your zuallet. Ant as long as there is enough money, it can be done."

C: "I don't think that one should thint in one' specialist direction, here one has to think holistically, globally... Here the economists cannot simply think in a stoie-pipe, they have to take into consideration all the other things. I think this is immoral. 
Focus Groups in Integrated Assessment: A Micro-Cosmos for Reflexive Modernization The relevance of moral reasoning is reaffirmed by the following interchange in
another IA-focus group:

Mot: "What reason zuould there be in your opinion to introduce policy mensures to
protect the climate system?".

A: "Well, simply my good conscience. I feel better when I have done something. When for example in the morning, zulien I take a shower, I do not waste the cold water which comes first, but put this into a bucket, for my flowers... This is very little, this is half a liter. But for me they have already been saved.

Or, in another context:

A: "Nobody knows, what is really going to happen in the coming thirty years. ..."

$B:$ "... but you know already that you don't let your car standing with a running engine in front of the garage. That's the thing you already know.

One might try to fit this line of argument in a frame of simple modernization by invoking the "low-cost hypothesis" of environmental concern (Diekmann, 1996). According to this hypothesis, moral recognition is a good like any other, and people will pursue it as long as it does not cost them much. As soon as the pursuit of moral recognition becomes more costly, however, a trade-off sets in and benefit cost analysis can be seen to operate. While there may well be a considerable portion of truth in this hypothesis, the evidence from the focus groups also shows that people do experience a clear contradiction between a benefit-cost approach to climate change and a moral judgement about the same issues. This contradiction deserves closer scrutiny.

On the one hand, we may see the moral approach as a relic from older, pre-modern times. On the other hand, it may be a seed of reflexive modernization, an attempt to embed processes of preference selection and preference formation in dialogical relations of accountability. The evidence available so far from our IA-focus groups is too limited to settle this issue; further research is needed for this purpose. But the evidence is clear on one point: simple modernization is far from offering the takenfor-granted background of our IA-focus groups.

\subsection{Reflexive Modernization}

We have seen in section 2 that reflexive modernization implies a subtle relationship between everyday knowledge and expert knowledge. The latter is still a core component of the symbolic universe of reflexive modernization. However, now expert knowledge is continuously relativized by other expert knowledge. Rather than providing a unique authoritative solution to given problems, expert knowledge now provides elements for a creative process in which very different routes may be explored until a solution emerges out of collective negotiations and debates. Reflexive modernization leads to a post-traditional society not in the sense that traditions are not relevant, but in the sense that people choose the traditions from which they let their lives be shaped.

The IA-focus groups analyzed so far provide only preliminary material which may be used to refine the hypothesis of reflexive modernization in view of more 
comprehensive tests. Still, it is remarkable how lay people deal with expert knowledge about environmental risks engendered by modernization. The unambiguous evaluations and expectations which went along with simple modernization are superseded by highly ambivalent ones. But this does not lead to an unwillingness or inability to engage in reasoned debate, quite the opposite. IAfocus groups are a promising approach to social research precisely because they offer a platform for such debate about problems for which no unique solution should be expected.

In the following we have selected quotes from our focus groups which to us seem relevant for these concepts, and have tried to generate more differentiated pictures from these.

\subsubsection{Re-assessing Technical Progress}

We have already given some examples of fear of progress expressed in the focus group debates. However, critical reflection of technical progress can go further by considering the double-sided nature of technical progress, which generates new problems as it solves existing ones. Such critical reflections were also explicitly expressed in the debates of our focus groups as for example in the following statement:

"Yes, this is generally the problem of humankint. Man thinks of himtself as such an intelligent being. He does research and deielopment and can not judge the impacts of his research at all. Well, if you consider the chemical industry. It doesn't matter what - even with fertilizers and pesticides - they all thought once that they are doing something good. And then more and more catnstrophes have occurred. ...

I believe zue humans are highly talented in developing something, seeing that it is not good at all, but instent of taking that thing back de'eloping something to correct the mistake. And so i'e uork continually on our mistakes trying to correct them insteat of simply saying: No, that was not goot at all, what I did there. That has to be totally removed. ..."

Reflexive modernization takes the expert knowledge provided by science into account, but it does not take it for granted. The way expert knowledge is actually incorporated in discourses of laypersons can be well illustrated with the conversations of our IA-focus groups. Here expert knowledge is actually incorporated in discourses of laypersons, and neither ignored nor simply refused:

Mod: "How do you see this for industrialized countries? Does energy use increase, or does it stay constant?"

A: "Constant, I think. Energy use may become a bit more economical, e.g. through new technologies, but use will then increase a bit, because one wants a bit more luxury. Efficiency increases, but then more goots are produced."

B: "That energies are better used. E.G. the cars atith their 10 l use."

Mod: "What would you say about temperature change? How will it develop in your opinion?"

C: "But zuhen temperature increases in the worst case it can happen that, who knows, polar caps melt, the gulf stream stops, anit a new ice age starts. Therefore, it is without grounding assumptions in specific developments, zuliat industry is doing. The development seems rather a woderate increase, mayle even a dramatic increase." 
A crucial difference between simple and reflexive modernization concerns the awareness of scientific uncertainties. Simple modernization assumes that scientific reason will be able to find the ansivers required for problem solving, and that scientific knowledge comes with the stamp of certainty. But focus group participants were aware of disagreements within science and did not think that the experts know
all answers:

"Is there a consensus on climate change? There are different opinions. There are those
who say yes, it has already begun and this and that. And the others say no, this is just
a fluctuation and it is going down again. There is not really a uniform consensus, as
far as I know, how far there is climate change, I mean climate change caused by
mankind..." Clirnate change is perceived as a complex phenomenon. Accordingly, a whole array of developments is taken into account:

Mod: Which figure wans the most thrilling, interesting, unusual or surprising one?

A: (impressed) "Population groilth. [...]"

Mod: "In your opinion population was the most interesting variable. Have there been other variables as well?"

B: "The development of different temperatures worlituide. That such extreme differences are supposed to emerge zuas interesting, too. That this has been presented so ivididy."

Realizing that in the case of climate change remoring uncertainties is not possible came as a kind of shock to some IA focus groups:

"The crucial novelty for me was that these uncertainties among scientists are still so high, or that it can be claimed that they are so high, this is someinhat surprising for me. I was very surprised that these measurements or how one wants to call this, documentations of facts, that in general they are not considered as completely ivell founded. This has astonished me. I thought there was more certainty in predicting developments; that meanithile more facts hat been collected; this I would have thought."

The relevance of such uncertainties for policy making are clearly perceived:

"What, nobody can tell me, if the sea lea'el rises by $30 \mathrm{~cm}$, what will happen? [...] If I were a politician, I would first of all want to kinow, as long as noboty can tell me, Hamburg ivill go under, or The Netherlands will disappear, that I am not willing to react in any zuay. I started from the assumption that one knowis, if the sen level rises by one meter, what the consequences will be. And now in a sense nobody can tell me, and I am now the Politician, who ... [sentence ends here].

The disappointment about scientific uncertainties might lead to a reinforcement of a perspective of simple modernization, e.g. by saying that much more research money and possibly better researchers should be assigned to the task. Or it might lead to a generalized mistrust in scientific expertise. Reflexire modernization implies a more subtle attitude, a willingness to deal with the unavoidable uncertainties of expert knowledge while actively using it as far as possible.

One of the salient features of the IA-focus groups is precisely the ability to tolerate the tension between knowledge and uncertainty in the use of experts and their products. An especially explicit statement in this direction has been reported by Querol and Tabara (1997) from a focus group within the Spanish part of the ULYSSES project: 
Focus Groups in Integrated Assessment: A Micro-Cosmos for Reflexive Modernization

\begin{abstract}
"Probably it's convenient that someone reminds us ... the scicntists, the media,... It's important that they talk, even if they contratict each other. This make's me reflect if I agree zuith on or the other. I think that reflection is important; because if I was going to try. within my possibilities, to take some mensure in my house, and if everybody made the same, then it rould be possible to aroid and to solve certain problems, wouldn't it?"
\end{abstract}

\title{
4.2.2 Experts and Models
}

As we have already noticed, the willingness of the IA-focus groups to debate climate change as a serious issue already implies a basis of trust towards the experts without which there would be no awareness of either increasing $\mathrm{CO}_{2}$-concentrations or the resulting dangers of climate change. On the other hand this trust is far from unconditional. Statements like the following one express a typical attitude:

"Experts zuill always find some other relations or they zuill mistrust single experts or variables, that therefore such things, ruhere one really needs to find a consensus, zulcere one actually even needs to take action, that such things get lost in the expert panel."

The ambivalent relation to experts translates into an awareness of the relativity of their products, as with the computer models used by the groups:

Mot: "Did you find the moitel plausible or rather the opposite?

A: "I think that the model or the question or the perspectio' from which I start, influences the result. This is as ath other information, TV transmissions etc. how does the one take ... [sentence stops here]. So on one hand there is tile information material, on the other hand is the one who receives this material, atell. depending on where he stands or how he listens. This has quite a consequence on how he deals with it and how he can encode it. I consider this to be a rather hot spot in this whole discussion. I think this is being used in politics in rather smart abis, to make this plausible or to make that plausible. I nearly have the impression, weil. if I have made up my mind beforehand, I find the facts and the right arguments ard the logic also and zwherever can I sell this? And the other one aliways stands there andi says, it is not compelling, the facts and so on. Therefore, a certain danger ..."

$B$. Things can be manip

A 'With such models."

Again, the interesting feature is the reflexive balance in which con,puter models meet neither blind trust, nor wholesale rejection:

A: "This with computer program [name eliminated] I found somei" express it in one way: It was not transparent. Today for example the other model, you have highlighted things w'hich you consideret irritating. To ave presented with a few core points. [...]

be important,

B: Where the latter program obviously is also simpler, the other one is far more complex and much more ...[unintelligible word].

But it is not so il sory, $c \quad$ sentence ents her

B: Ant it is interactive. [...]. Ant it is easy to handle, it is clearly arrang

A: And aboie all one has hard facts, somehou' [approval by the group ith which onte can do something. And this is something which I missed with the other diel.

The following statement blends a balanced view of experts with a balanced view of their products. The interesting fact is how self-evident, "taken-for-granted" the 
Focus Groups in Integrated Assessment: A Micro-Cosmos for Reflexive Modernization

statement sounds - at least in this group, where the statement did not meet any resistance - reflexive modernization has already displaced its ancestor to a considerable extent.

Mout: "Would you trust such a model?"

A: "It always depends on who enters the data. This means, what data base I build, zuhat clanges I make with the data..."

\subsubsection{The Merits of Different Traditions and the Hegemony of Current European Culture}

In the debates of our focus groups we also found indications that in the view of the problems created by modernization itself, an appreciation was sometimes expressed for features of the knowledge bases and lifestyles associated with other traditions than modern society:

"I am thinking of another problem. I am zuorking as a musician, and I have once read a study about how we deal with time. I think, compared to medtieval times for example, the concept of time or the division of time have totally changed. And today zue even think in hundredths or thonsandths parts of seconts and so on. Well, sometimes I also have problems with that."

In the first part of the following quote the feeling is expressed that although people were not really different in different ages of our history, at least the implications of man's nature were not so serious:

"But has man really changed so much, compared to earlier times? Hasn't man been alivays an egoist? Only todin that has far bigger impacts. Toitay man has much more poiver, much more possibilities. If you look at the image of man of the philosophers you see - well basically there were tivo directions. On the one side those who said that man is a wolf and we need the state to keep him a tight reign on him. And the others who just said that man is good by nature. And this kind of leads to the idea of communism. We are goot and we can build up something together. And this has failed all ouer the world, or is just failing now. Which in the end show's that man is by nature an egoist and rather bad - in quotation marks. Because of this it is one of my great fears that there is no solution for this ihole problem."

In the second part of this quotation this focus group participant tries to understand today's situation by looking at different traditions of thought as frames of reference, and comparing their implications with the situation perceived today. His conclusions for our chances of a bright future are rather bleak. In the following section we will look at different images of the future.

Inspired by the presentation of the computer model IMAGE, one participant realized a cultural bias of expert assessments. From the point of view of the participant, the specific European view of and technical approach to the problem neglects assessments and evaluations from other countries and continents particularly from the $3^{\text {rd }}$ world. However, the example transcribed below, remained unique in all of the Frankfurt groups. Interestingly, the thoughtful and pausing participant distinguishes between an European and a real point of view towards the climate.

"I am still thinking about ..., I don't know' ..., were all the experts who aworked on this model Europeans? For me, the basis scenario seemed very culturally biased, the whole attitude toward life in general, ver. Europenn. I would be inter sted to get more information about how Africans imagine this problem. ... Because this (output) 
Focus Groups in Integrated Assessment: A Micro-Cosmos for Reflexive Modernization

confirms all the information tue already have in Europe, it confirms also (Europcan) policy, because onc can also interpret the statistics in a positive way. ... This is again a European point of view, not a real one. ... It is an attempt to regard the problem from a worldwite point of view, but it consisted only of an European one."

\subsubsection{Looking for Solutions}

The problem of climate change is often analyzed as a social dilemma: even by incurring considerable costs, no individual can make a significant contribution to the reduction of emissions; therefore, it is rational for each individual to be a free rider. In relation to environmental problems, this kind of problem is known as the tragedy of the commons. With regard to the problem of social order, the same kind of problem lay at the very origins of simple modernization. Thomas Hobbes justified the use of force by the government as the only way to overcome the social dilemma implied by endemic civil war.

According to the social dilemma perspective, the problem of climate change arises because there is no world government or equivalent body which would be able to enforce global emissions reductions. The following statement has some similarities with this analysis:

"...it is surprising, when policy measures like, e.g., a $\mathrm{CO}_{2}$-reduction are assumed, they do not have a lasting effect in the model, that after a short inflection it rises again. [...] This in turn for me at least perhaps but also for others has the worry that other people who deal less serionsly with the problem reach the conclusion that they can say, I can leave my car at home as much as I want and take the bike for shopping or for whatever, at any rate I do not help the development, or do not hinder the negative development.

However, the intuition expressed by the statement cannot really be grasped by an analysis framed purely in terms of a social dilemma. The statement conveys a feeling of hopelessness which is based in the lack of a perceived solution. It calls for a search to find and design new ways of dealing with the problem. Such a search may need to tackle the difficulties of a social dilemma, but it may also put into question important features of modernization as it has been experienced so far:

"Here the concept of waste-oriented society comes into my mind. How dit we come to
the waste-oriented society? Because production has become cheaper and cheaper. Costs
did not play a role, so that w' could afford it anytime. We do not mend stockings
anymore, a'e do not bring shoes to the shoemaker, we do not repair trousers or a shirt
or anything alike [...] we throw' it an'my and buy a new shirt for 18 or 20
Deutschmark, depenting on one's wallet. What w'e forget is the ahole string of
consequences which this entails.

Again, this statement is reminiscent of a standard piece of analysis in contemporary environmental economics: the social dilemma which lies behind environmental problems can be solved by internalizing the external effects leading to the dilemma. This is the basic rationale for the introduction of "green" taxes by government; at the global scale this leads again to the problem of world governance. But again the statement expresses an intuition which goes beyond the social dilemma perspective. What is at stake is the overall thrust of simple modernization, the lack of a reflexive search for institutional arrangements which will change the course of modernization, rather than overcoming obstacles to the prevailing course. 
This requires processes of social learning whose outcomes cannot be fully known in advance. But at least at some stages the conversation of the IA-focus groups implies a cautious optimism. After all, modern societies may meet the moral challenge raised by climate change and develop alternative ways of development which may be as viable as the one prefigured by simple modernization:

"If over centuries we are really dealing zuith our environment so as we have done, then one cannot turn around the people from one day to the next and fall from one extreme into the other. [...] Maybe I am a little optimistic here. Well, 15 to 20 years ago many things looked much different; with pesticides, herbicides, etc, as well. At least here in our region, at least in the industrialized countries other means have been found. Ok, it still goes into the Third World, to Africa. But this will change some day, too." 
Focus Groups in Integrated Assessment: A Micro-Cosmos for Reflexive Modernization

\section{Conclusion}

Three kinds of conclusions can be drawn, concerning first the hypothesis of reflexive modernization, second the methodology proposed, and finally policy making.

First, with regard to reflexive modernization, it is interesting to compare the results with the standard approach of decision theory. In this approach, each actors enters the stage, as it were, equipped with a preference ordering and a set of subjective probability judgements. These are not amenable to rational debate, but they may be modified by additional information either about other actors or about the world in general. It seems fair to associate this view of rational action with simple modernization. In studies about global environmental risks, it leads to the figure of the benevolent planner who uses neoclassical economics to optimize the trade-off between economic growth and environmental protection (e.g. Nordhaus, 1994,
Manne and Richels, 1995).

IA-focus groups, however, display debates about preferences and probability judgements, and these debates are as rational as any other ones to be observed in the groups. Such debates are a vital element of reflexive modernization. Modernization, because they accept the plurality of subjective interests and judgements, reflexive, because they offer and require forms of social accountability for such interests and judgements. Accordingly, a pluralist strategy in the assessment of global environmental problems seems appropriate (Pahl-Wostl et al., in press). Such a strategy will highlight different subjective probabilities, e.g. for extreme events, and it will represent different degrees of risk aversion in dealing with environmental
problems.

As long as the problem to be dealt with involves a simple trade-off between economic growth and environmental protection, however, even a highly reflective approach will end up by looking for an optimal balance in terms of whatever goals one may pursue. The benevolent planner remains in charge. Things are different when trajectories of possible societal developments bifurcate. With regard to problems like climate change this may be the case where technological choices lead to lock-in'situations because of sunk investments in infrastructure and in social knowledge (Hourcade, 1993). Such bifurcations mean that the economy cannot be treated as an optimizing machine with a well-identifiable equilibrium but rather behaves as an evolving complex system (Anderson et al., 1988, Dietz and Burns, 1992; see also Jaeger and Kasemir, 1996). The study of reflexive modernization, then, needs to combine the investigation of face-to-face conversations at the micro-level with a careful analysis of dynamic features of social and economic structures at the macro-level.

This challenge leads us to our second group of conclusions, concerning methodology. In fact, one of the reasons IA-Focus Groups are a promising research tool is the possibility to combine the use of such groups for micro-investigations of the dynamics of everyday knowledge with the use of IA-models for the study of large-scale human ecological systems. This combination enables researchers to introduce new arguments in a given social setting and to study their subsequent dynamics: what inform ?tion is used, and how, and what information gets discarded? Along these lines, IA-focus groups can be used as a social micro-cosmos akin to those 
used in biological ecology. There, the population dynamics of an organism is sometimes studied by establishing a small ecosystem with closed boundaries and introducing the organism in question in the system. IA-focus groups provide similar opportunities for studying the cultural dynamics of new elements of everyday knowledge. The hypothesis of reflexive modernization implies that such studies may be especially fruitful at the interface with the expert knowledge produced by scientific institutions.

At a methodological level, then, the first conclusion is that IA-focus groups are a suitable instrument for the study of reflexive modernization. Further conclusions refer to future improvements of this kind of instrument. One problem is the recruitment of participants. Basically, nearly every sampling design is feasible, but recruitment may become quite expensive. Research institutions interested in using IA-focus groups on a broad scale, therefore, need access to a good sampling network. Nowadays, only few institutions have such access. Outsourcing recruitment to marketing firms is one solution, but researchers need to be aware of both the costs and the possibly changing course of the discussions. As the experience in the ULYSSES-project shows, groups of randomly selected participants tend to be more homogeneous than groups composed with regard to representative sociodemographic or other recruitment criteria.

An alternative is the careful design of cheap sampling designs. For example, it is quite hard to get a decision maker to participate in a group drawn at random from the general population: very often, time constraints will be insurmountable. On the other hand, it is much easier to get decision makers to participate in policy panels where they interact with each other. Such panels are often experienced as very satisfactory, and this may even induce some participants to engage in a subsequent group with mixed composition.

Another area for improving IA-focus groups is the development of variations in design. For example, in many cases it may be useful to run groups which meet only once. Under these conditions, there is no way of producing a citizen report, and a computer model would indeed have to be very user friendly to be suitable as an input to such a group. Nevertheless, we have made positive experiences with such "rapid IA-focus groups" (Jaeger and Willi, 1997), and further work in this area might lead to important practical applications. Moreover, even in multi-session groups one may want to work with other inputs as computer models and other outputs as citizen reports. Only substantial research experience can help to identify which options are most sensible under what kind of conditions. And new problems will always lead to further refinements and variants of existing ways of proceeding.

As a last methodological point, data analysis deserves special attention. In the present paper, we have used ideal types and iterative interpretations. Strauss' (1990) work offers many hints for further improving this kind of methodology. However, we would oppose his neglect of broader theoretical issues: the hypothesis of reflexive modernization is a promising example for how such issues can guide empirical work in IA-focus groups. Other kinds of data analysis, ranging from computer based statistical computations to free-wheeling philosophical interpretations, are possible and should be explored. And clearly, data analysis is not independent from research design (Shye et al., 1994). IA-focus groups are not contemplative observations of a reality given independently from any observer. They are more akin to participatory action research (Whyte, 1991), or even to quantum mechanical experiments: active 
interventions to bring about a specific reality. What can be learned, then, is where researchers meet with resistance and sometimes insurmountable obstacles, and where they find a positive resonance in the social world. In the groups discussed here, the former was the case with approaches of simple modernization, while reflexive modernization belonged to the latter category.

Finally, the transition from simple to reflexive modernization has important implications for policy making. Ideas of "dialogic democracy" (Giddens, 1994a), suggestions of "round tables" mixing stakeholders, experts, and citizen (Beck, 1994) have been proposed, and the literature on participatory planning reviewed in section 3.1 is clearly relevant here. Nevertheless, we are a far cry from plausible institutional arrangements to deal with global environmental risks under conditions of reflexive modernization.

IA-focus groups may well have a role to play here. However, this requires the design of two more interfaces. As science looses its automatic claim to authority under conditions of reflexive modernization, the media acquire an additional role: they become an important mechanism of selection for scientific knowledge claims (and actually also for scientists' claims to public resources). Therefore, designing a sensible interface between IA-focus groups and mass media may become an important task for the use of such groups in policy making. Also, the interface between IA-focus groups and policy makers themselves is still in its infancy. Presently, there is a growing awareness among policy makers that the world of simple modernization is becoming increasingly problematic. How to respond to this situation is an open question for practitioners as well as for theoreticians. Maybe sensible answers can be found only in a dialogue where both learn from limited and reasonably well documented experiences. IA-focus groups are one possibility to foster such a dialogue. 


\section{Bibliography}

Alcamo, J. (ed.). 1994. IMAGE 2.0: Integrated Modeling of Global Climate Change. Dordrecht: Alcamo, J., R. Shaw, and L. Hordijk. 1990. The Rains Model of Acidification: Science and Strategies
in Europe. Doordrecht: Kluwer.

Alexander, J. C. and P. Smith. 1996. Social Science and Salvation: Risk Society as Mythical Discourse. Zeitschrift fïr Soziologie Vol. 25 4:251-262

Amy, D. R.. 1987. The Politics of Environmental Mediation. New York: Columbia University Press

Anderson, P.W., K.J. Arrow, and D. Pines. 1988. The Economy as an Evolving Complex System, Santa Fe Institute Studies in the Sciences of Complexity.

Bailey, P., C. Gough, M. Chadwick, and G. McGranaham. 1995. Methods for IEA: Research Directions for the European Union. Paper presented at: Workshop on IEA. European Commission, DG XII-D5/ Joint Research Center. Brussels 18-20 May 1995.

Barbour, R. and J. Kitzinger. 1999. Developing Focus Group Research. London: Sage

Baumann, Z. 1989. Modernity and Ambivalence. Cambridge: Polity

Beck, U. 1986/ 1992. Risk Society: Towards a N'ew Moderniñ. London: Sage

Beck, U. 1994a. Towards a Theory of Reflexive Modernization. in: Beck, Ulrich, A. Giddens and S. Lash. 1994. Reflexive Modemization: Politics, Tradition and Aesthetics in the Modern Social Order. Cambridge: Polity

Beck, U. 1994b. The Reimvention of Politics. London: Sage

Beck, U., A. Giddens and S. Lash. 1994. Reflexive Modernization: Politics. Tradition and Aesthetics in the Modern Social Order. Cambridge: Polity

Berger, P.L., Luckmann, T. 1990/ 1966. The Social Construction of Renlity. A Treatise in the Sociology of Knowledge. Penguin, London.

Berger, P.L. 1990/ 1969 Rumor of Angels. New York: Doubleday

Bostrom, A., G. Morgan, B. Fischoft. 1994. What do People Know About Global Climate Change?. Risk Analysis 14:959-969.

Bostrom, A., B. Fischoft, and G. Morgan. 1992. Characterizing Menthal Models of Hazardous Processes: A Methodology and an Application to Radon." Journal of Sociological lssues 48:85-100.

Burgess, J. , M. Limb, and C.M. Harrison. 1988. Exploring Environmental Values Through the Medium of Small Groups. Environment and Planning. 20:309-326.

Buttel, F. H. and P.J. Taylor. 1992. Environmental Sociology and Global Environmental Change. A Critical Assesssment. Society and Natural Resources 5:211-230.

Byers, P.Y., and J.R.Wilcox. 1991. Focus Groups: A Qualitative Opportunity for Researchers. Journal of Business Communication 28 (1): 63-78.

Caulfield, Janice and John Minnery. 1994. Planning as Legitimation: A Study of the Brisbane Strategy Plan. International Journal of Urban and Regional Research. 18:673ff.

Conner, J., K. Richardson. N. Fenton. 1991. Nuclear Reactions. London: John Libby:

Cosby, N. 1995. Citizen Juries: One Solution for Difficult Environmental Questions. in: Fairness and Competence in Citizen Participation. edited by Renn. Ortwin. Thomas Webler, and Peter Wiedemann.1995. Dordrecht: Kluwer.

Dahinden, U., L. Bieri, R. Rudel. 1994. Regional Communication About Climate Change - A Case Study from Alpine Regions." Paper presented at: XIII World Congress of Sociolog.: Bielefeld. 
Focus Groups in Integrated Assessment: A Micro-Cosmos for Reflexive Modernization Desvouges, W.H. and K.V. Smith. 1988. Focus Groups and Risk Communication: The 'Science' of
Listening to Data. Risk Analysis 8(4): 479-484.

Dienel, P.C. and O. Renn. 1995. Planning Cells: A Gate to 'Fractal' Mediation. in: Fairness and Competence in Citizen Participation. edited by Renn, Ortwin, Thomas Webler and Peter Wiedemann.1995. Dordrecht: Kluwer.

Dienel, P.C. 1992. Dic Planungszelle. Opladen: Westdeutscher Verlag.

Dietz, T. and T.R. Burns. 1992. Human Agency and the Evolutionary Dynamics of Culture. Acta
Sociologica $35: 187-200$

Dowlatabadi, H. 1994. Integrated Assessment of Climate Change: An Incomplete Overview." Pp. 103104 in Integrative Assessment of Mitigation, Impacts, and Adaption to Climate Change, edited by N. Nakicenovic, Richels, Toth. Laxenburg. Austria: IIASA.

Dürrenberger, G., J. Behringer, U. Dahinden, A. Gerger, B. Kasemir, C. Querol, R. Schüle, D. Tabara. F. Toth, M.B.A. van Asslet, D. Vassilarou, N. Willi, C.C. Jaeger. 1997. Focus Groups in Integrated Assessment - A manual for a participatory tool. Working paper ULYSSES WP-97-2. Darmstadt University of Technology, Center for Interdisciplinary Studies in Technology' (zit@tu-darmstadt.de).

Dunlap, R.E. and W.R. Cation Jr. 1994. Toward an Ecological Sociology: The Development, Current Status, and Probable Future of Environmental Sociology." Pp. $11-31$ in Ecology, Society and the Quality of Social Life, edited by W. V. D'Antonio and e. AI. New Brunswick: Transaction
Publishers.

Folger, Joseph P. (ed.) 1994. Nen Directions in Mediation: Communication Research and Perspecrives. Thousand Oaks: Sage

Funtowicz, S. and J. Ravetz. 1991. A New Scientific Methodology for Global Environmental Issues." in Ecological Economy, edited by Robert Costanza. New York: Columbia.

Funtowicz. S. and J. Ravetz. 1992. Three Types of Risk Assessment and the Emergance of PostNormal-Science. in: Social Theories of Risk. Edited by Sheldon Krimsky and Dominic Golding. Westport, CT: Praeger

Funtowicz, S. and J. Ravetz. 1994. Uncertainty, Complexity and Post-Normal-Science. Environmental Toxicology and Chemistry 13:12

Giddens, A. 1994a. Beyond Left and Right. Cambridge: Cambridge: Polity.

Giddens, A. 1994b. Living in a Post-Traditional Society. in: Beck. Ulrich. A. Giddens and S. Lash. 1994. Reflexive Modernization: Politics, Tradition and Aesthetics in the Modern Social Order. Cambridge: Polity

Giddens, A. 1990. The Consequences of Modernity. Cambridge: Polity

Greenbaum. T.L. 199S. The Handbook of Focus Group Research. London: Sage

Godard. O. 1992. Social Decision Making in the Context of Scientiftic Controversies." Global Environmental Change :239-249.

Habermas. J. 1982. Theorie des kommunikariven Handelns. Frankfurt: Suhrkamp.

Hirsch-Hadorn, G. 1997. Webers Idealtypus als Methode zur Bestimmung des Begriffsinhaltes theoretischer Begriffe in den Kulturwissenschaften". Joumal for Genteral Philosophy of Science 28: 275-296.

Hourcade, J.C. 1993. Modelling Long-Run Scenarios. Methodology Lessons from a Prospective Study on a Low CO2 Intensive Country. Energ. Policy: March, 309-326.

Jaeger, C.C., and B. Kasemir. 1996. Climatic risks and rational actors. Global Environmental Change 6(1): 23-36.

Jaeger, C.C. 1996. Humanökologie und der blinde Fleck der Wissenschaft". In: Diekmann, A., and Jaeger, C.C. Umweltsoziologie. Special Issue Nr. 36 of Kölner Zeitschrift für Soziologie undSozialpsychologie. 
Focus Groups in Integrated Assessment: A Micro-Cosmos for Reflexive Modernization

Jaeger, C.C., O. Renn, E. Rosa, and T. Webler. 1999. Risk, Uncertainy and Rational Action.
forthcoming

Jaeger, C.C., M. Chadwick, B. Wynne, S. Funtowicz. M. Giaoutzi, S. Giner, F. Toth, J. Jäger, G.
Dürrenberger, J. Ravetz, C. Casilli. Dürrenberger, J. Ravetz, C. Casilli. 1995. ULYSSES: Urban Lifestyles, Sustainability and Integrated
Environmental Assessment. A RTD proposal for Framenort Progran Climate. Darmstadt: University of Technology

Jaeger, C.C. and N. Willy. 1997. Zukunftsvision 1000 Watr-Gesellschafr? Ms., EAWAG.

Joss, S., J. Durant. 1994. Consensus Conferences. Basel: BATS-Agency.

Kasemir, B., M.B.A. van Asselt, G. Dürrenberger, C.C. Jaeger. 1998. Integrated Assessment: Multiple Perspectives in Interaction. Accepted for International Journal of Environment and Pollution,
special issue on Methods and Models for Decision Support.

Kasemir, B., J. Behringer, B. De Marchi, C. Deuker, G. Dürrenberger, S. Funtowicz, ^ Gerger, M. Giaoutzi, Y. Haffner, M. Nilsson, C. Querol, R. Schüle, D. Tabara, M. van Asselt, D. Vassilarou, N. Willi, and C.C. Jaeger. 1997. Focus Groups in Integrated Assessment: The ULYSSES pilot experience. Working paper ULYSSES WVP-97-4, Darmstadt University of Technology, Center for Interdisciplinary Studies in Technology (zit@tu-darmstadt.de).

Kasemir, B.. C.C. Jaeger, G. Dürrenberger. 1996. Embedding integrated assessment models in social discourse. Science and Public Policy 23 (2): 124-125.

Kasemir, B.. C.C. Jaeger. G. Dürrenberger. 1996. Embedding integrated assessment models in social discourse. Science and Public Policy 23 (2): 124-125.

Kasemir, B. et al. 1999. Fear. Hope and Ambiguin: Citizens' Perspectives on Climate Change and Energv' Use " Working paper ULYSSES WP-99-1, Darmstadt: University of Technology, Center for Interdisciplinary Studies in Technology (zit@tu-darmstadt.de).

Kempton, W.. 1991a. Lay Perspectives on Global Climate Change." Global Environmental Change
1:183-208.

Kempton, W.. 1991b. Public Understanding of Global Warming." Society and Natural Resources 4:331-345.

Lash. S.. 1994. Reflexity and its Doubles: Structure, Aesthetics, Community. in: Beck, Ulrich, A. Giddens and S. Lash. 1994. Reflexive Modernization: Politics. Tradition and Aesthetics in the Hodern Social Order. Cambridge: Polity.

Lash, S. and J. Urry. 1994. Economies of Signs and Space. London: Sage.

Löfstedt, R. 1991. Climate Change Perceptions and Energy-use Decisions in Northern Sweden." Global Environmental Change 1:321-324.

Lynn, F.M. and G.J. Busenberg. 1995. Citizen Advisory Committees and Environmental Policy: What We Know, What's Left to Discover." Risk Analysis 15:147-162.

Merton, R.K. 1987. The Focused Interview and Focus Groups: Continuities and Discontinuities. Public-Opinion-Quarterly 5l(4): 550-566.

Merton, R.K. and P.L. Kendall. 1946. The Focused Interview. American Journal of Sociology 51 : 541 557.

Manne, A. and R. Richels. 1995. The Greenhouse Debate: Economic Efficiency, Burden Sharing and Hedging Strategies." The Energy Journal 16(4).

Morgan, D. L. and R.A. Krueger. 1997. The Focus Group Kit". Six Volumes. London: Sage

Nakicenovic, N., W.D. Nordhaus, R. Richels, and F.L. Toth. 1994. Integrative Assessment of Mitigation, Impacts, and Adaptation to Climate Change. CP-94-9. Laxenburg. Austria: IIASA.

Nordhaus, W.D. 1994. Managing the Global Commons. The Economics of Climate Change. Cambridge, MA.: MIT Press. 
O`Hara, S.. 1996. Discursive Ethics in Ecosystems Valuation and Environmental Policy." Ecological
Economics 16:95-107.

Pahl-Wostl, C., D. Imboden, C.C. Jaeger, and et al.. In press. Uncertainty In Climate Change." in Viens form the Alps, edited by P. Cebon, U. Dahinden, H. Davies, D. Imboden, and C. C. Jaeger.
Boston: MIT.

Parson, E.A. 1994. Searching for Integrated Assessment: A Preliminary Investigation of Methods and Projects in the Integrated Assessment of Global Climatic Change." Paper presented at the 3rd Meeting of the CIESIN-Harvard Commission on Global Envirommental Change Information Policy.
Boston

Querol, C., and Tabara, D., It's important that they talk, even if they contradict each other" - The Barcelona Pilot IA-Focus Groups within ULYSSES, in: Kasemir, B. et al, 1997, Focus Groups in Integrated Assessment: The ULYSSES pilot experience, Working paper ULYSSES WP-97-4, Center for Interdisciplinary Studies in Technology, Darmstadt University of Technology.

Renn, O., Th. Webler, and P. Wiedemann (eds.). 1995. Fairness and Competence in Citizen Participation. Dordrecht: Kluwer.

Renn, O. 1993. Public Participation in Decision Making: A Three Step Procedure." Policy Sciences Vol. 26

Ringer, Fritz (1997). Max Weber's Methodology - The Unification of the Cultural and the Social Sciences". Cambridge, Mass.: Harvard University Press

Robinson. J.B. 1995. On the Very Idea of Integrated Environmental Assessment." Paper presented at: Workshop on IEA. European Commission. DG XII-D5/ Joint Research Center 18-20 May 1995. Brussels

Rotmans, J. and B. de Vries (eds.). 1997. Perspectives on Global Change: The TARGETS Approach. Cambridge: University Press

Schlumpf, C., Behringer, J., Dürrenberger, G. and Pahl-Wostl, C. 1998. submitted: The Personal CO2-Calculator: A modeling tool for Participatony Integrated Assessment Methods.

Schïle, R. 1996. Advanced Tools for Integrated Assessment. Paper presented at the Annual Meeting of the American Sociological Association, 16-20 August. New York

Schüle, R. 1999a. IA - Focus Groups in the Frankfurt Area - A Collection of Inputs and Outputs". Darmstadt University of Technology (schuele@ifs.tu-darmstadt.de).

Schüle, R. 1999b. Uncertainty: Ideal Types and Reflexive Modernization. Unpubl. Ms. Darmstadt University of Technology:

SEI - Stockholm Environment Institute. 1996. POLESTAR: Sistem Manual. POLESTAR Series Report No.2. Stockholm, Sweden

Sellnow, R. 1994. Verkehrsforum Heidelberg." in Umweltkonflikte - Verfahren zu ihrer Lösung. edited by Frank Claus and Peter Wiedemann. Taunusstein: Blottner.

Shackley, S. and B. Wynne. 1995. Global Climate Change: The Mutual Construction of an Emergent Science-Policy Domain. Science and Public Policy 22 (4): $218-230$.

Shye, S. and Dov Elizur (with M. Hoffman). 1994. Introduction to Facet Theor: Content Design and Intrinsic Data Analysis in Behavioual Research. Thousand Oaks: Sage

Spaargaren, G. 1997. Ecological Modernization Theory and the Changing Discourse on Environment and Modernity. Paper presented at the IS.A/RC-24 conference 'Sociological Theory and the Environment: Woudschoten. Netherlands, 1997.

Stewart, D.W. and P. N. Shamdasani. 1994. Focus Groups - Theon and Practice. London: Sage.

Strauss, A. and J. Corbin. 1990. Basics of Qualitative Research: Grounded Theory. Procedures and Techniques. Newbury Park, CA: Sage 
Toth, F. 1994. Practice and Progress in Integrated Assessment of Climate Change: A Review." Pp. 332 in Integrative Assessment of Mitigation, lmpacts, and Adaptation to Climate Change, edited by N. Nakicenovic, Richels. Toth. Laxenburg, Austria: IIASA.

Toth. F. 1995. Integrated Environmental Assessment: Concepts and Methods." Paper presented at the Workshop on IEA, European Commission, DG XII-D5/ Joint Research Center I8-20 May 1995.
Brussels Weber, Max 1946/ 1922. The Methodology of the Social Sciences". Tranl. and ed. Edward A. Shils
and Henry A. Finch. New York: Free Press

Weyant, J., O. Davidson, H. Dowlatabadi, J. Edmonds, M. Grubb, E.A. Parson, R. Richels, J. Rotmans, P. Shukla, R.S.J. Tol, W. Cline, S. Frankenhauser. 1996. Integrated Assessment of Climate Change: An Overview and Comparison of Approaches and Results. In J.P. Bruce, Hoesung Lee and E.F. Haites (eds.) Economic and Social Dimensions of Climate Change. IPCC (Chapter 10). Cambridge: University Press.

Wynne, B. 1996. May the Sheep Safely Graze? A Reflexive View of the Expert-Lay Knowledge Divide, in: Lash, Scott. Brionislaw Szerszynski and Brian Wynne. 1996. Risk, Environment and Modernitr. London: Sage.

Young. S.C. 1996. Promoting Participation and Community-Based Partnerships in the Context of Local Agenda 21: A Report for Practitioners". Manchester: Gouvernment Department and Manchester University.

Whyte, W.F. 1991. Participatong Acrion Research. London: Sage. 